\title{
PENERAPAN MODEL PEMBELAJARAN KOOPERATIF TIPE TEAMS GAMES TOURNAMENT BERBANTUAN MEDIA KARTU UMBUL UNTUK MENINGKATKAN PEMAHAMAN KONSEP SISWA SEKOLAH DASAR
}

\author{
Rissa Prima Kurniawati \\ Universitas PGRI Madiun, Jalan Setia Budi 85 Madiun \\ Email: rissaprimakurniawati14@gmail.com
}

\begin{abstract}
The purpose of this research is to improve the understanding of the concept of the fourth grade students of Public Elementary School Dinden 1 Kwadungan Ngawi (SDN Dinden 1 Kwadungan Ngawi) by implementing cooperative learning model of Teams Games Tournament type (TGT) with the help of umbul card. The approach used in this study is a qualitative approach and this type of research is a classroom action research (CAR). The subjects of the research in this study were students of Class IV SDN Dinden 1 Kwadungan Ngawi which amounted to 14 students. The data collection in this research is the learning implementation plan (RPP), student activity observation sheet, teacher observation activity sheet, student worksheet (lembar kerja siswa / LKS), test, and interview. The results showed that the percentage of Cycle I test results was $64.29 \%$ and the percentage of Cycle II test result was $92.86 \%$. So that the cooperative learning model of TGT type with the banner card on the sum of integers, the reduction of integers, and solving the problems related to addition and subtraction of integers can improve students' concept understanding from Cycle I to Cycle II that is $28.57 \%$.
\end{abstract}

Keywords: cooperative learning, teams games tournament, concept comprehension, media card umbul

\begin{abstract}
Abstrak: Tujuan penelitian ini adalah untuk meningkatkan pemahaman konsep siswa Kelas IV SDN Dinden 1 Kwadungan Ngawi dengan menenerapkan model pembelajaran kooperatif tipe Teams Games Tournament (TGT) berbantuan media kartu umbul. Pendekatan yang digunakan dalam penelitian ini adalah pendekatan kualitatif dan jenis penelitian ini adalah penelitian tindakan kelas (PTK). Subyek penelitian dalam penelitian ini adalah siswa Kelas IV SDN Dinden 1 Kwadungan Ngawi yang berjumlah 14 siswa. Pengumpulan data dalam penelitian ini adalah rencana pelaksanaan pembelajaran (RPP), lembar observasi aktivitas siswa, lembar aktivitas observasi guru, lembar kerja siswa (LKS), tes, dan wawancara. Hasil penelitian diketahui bahwa persentase hasil tes Siklus I adalah $64,29 \%$ dan persentase hasil tes Siklus II adalah $92,86 \%$. Sehingga model pembelajaran kooperatif tipe TGT berbantuan kartu umbul pada materi penjumlahan bilangan bulat, pengurangan bilangan bulat, dan menyelesaikan masalah yang berkaitan dengan penjumlahan dan pengurangan bilangan bulat dapat meningkatkan pemahaman konsep siswa dari Siklus I ke Siklus II yaitu sebesar 28,57\%.
\end{abstract}

Kata kunci: pembelajaran kooperatif, teams games tournament, pemahaman konsep, media kartu umbul

Kualitas kehidupan suatu bangsa sangat ditentukan oleh pendidikan. Pendidikan merupakan suatu kegiatan yang mempersiapkan siswa agar sanggup menghadapi zaman yang semakin lama semakin berkembang dengan pesat. Salah satu lembaga yang mewadahi pendidikan adalah sekolah. Sekolah merupakan lingkungan pendidikan formal untuk melaksanakan serangkaian kegiatan terencana dan terorganisasi (Winkel, 2004; Effendy, 2007). Pelajaran matematika di Sekolah Dasar seringkali menjadi momok bagi siswa. Anggapan demikian tidak lepas dari persepsi yang berkembang dalam 
masyarakat tentang matematika sebagai pelajaran yang sulit dan menakutkan. Hal itu karena matematika merupakan ilmu yang abstrak, penuh dengan lambang-lambang, angka-angka, rumusrumus yang sulit, dan terkadang membingungkan. Berdasarkan hasil observasi di sekolah, masih banyak siswa sekolah dasar yang belum bisa pelajaran matematika terutama pada penjumlahan, pengurangan, dan menyelesaikan masalah tentang bilangan bulat.

Berdasarkan laporan hasil ulangan pelajaran matematika Kelas IV SDN Dinden 1 Kwadungan Ngawi dapat dilihat bahwa hanya 5 orang dari 14 siswa yang mencapai kriteria ketuntasan minimal (65), dengan kata lain hanya 36\% siswa yang mencapai kriteria ketuntasan minimal yang ditetapkan. Berdasarkan hasil wawancara dan observasi awal, pembelajaran yang biasanya dilakukan oleh guru, yaitu menjelaskan materi, menulis di papan tulis dan siswa mencatat sesuai dengan penjelasan guru, memberikan contoh, dan terakhir memberikan latihan atau soal. Pembelajaran yang terjadi hanya satu arah. Model pembelajaran kooperatif memaksimalkan kegiatan belajar dengan cara mengelompokkan siswa ke dalam kelompok-kelompok kecil. Salah satu tipe dari model pembelajaran kooperatif yang mudah diterapkan pada pembelajaran adalah TGT. Salah satu langkah pembelajaran dari model pembelajaran kooperatif tipe TGT adalah permainan. Permainan ini dapat membuat siswa tidak jenuh terhadap pelajaran matematika (Arsyad, 2011; Asnawir dan Usman, 2002).

Suatu pembelajaran yang menyenangkan selain membutuhkan model pembelajaran juga memerlukan media pembelajaran. Melalui media pembelajaran, diharapkan proses pembelajaran dapat menjadi aktif dan menyenangkan. Salah satu media pembelajaran yang dilakukan di sekolah dasar adalah kartu umbul. Siswa sekolah dasar sering memainkan kartu umbul. Melalui media kartu umbul ini, dapat membantu siswa dalam memahami materi penjumlahan dan pengurangan bilangan bulat. Berdasarkan permasalahan pembelajaran matematika, maka tujuan penelitian ini adalah untuk meningkatkan pemahaman konsep siswa Kelas IV SDN Dinden 1 Kwadungan Ngawi dengan menenerapkan model pembelajaran kooperatif tipe TGT berbantuan media kartu umbul.

\section{METODE}

Peneliti ini mendeskripsikan penerapan model pembelajaran kooperatif tipe Teams Games Tournament (TGT) berbantuan media kartu umbul untuk meningkatkan pemahaman konsep siswa Kelas IV SDN Dinden 1 Kwadungan Ngawi. Oleh karena itu, pendekatan yang digunakan dalam penelitian ini adalah pendekatan kualitatif. Jenis penelitian ini adalah penelitian tindakan kelas (PTK). Rancangan penelitian ini mengacu kepada model Kemmis dan McTaggart yang setiap siklus masing-masing terdiri atas empat langkah kegiatan meliputi perencanaan (planning), pelaksanaan tindakan (action), observasi (observation), dan refleksi (reflection) (Arikunto, 2007; Aqip, 2006; Gunawan, 2016). Subyek penelitian dalam penelitian ini adalah siswa Kelas IV SDN Dinden 1 Kwadungan Ngawi yang berjumlah 14 siswa.

Data yang dikumpulkan dalam penelitian ini meliputi data hasil lembar kerja siswa, hasil tes siswa, hasil pengamatan aktivitas siswa dan guru selama proses pembelajaran, lembar wawancara, dan hasil tes siswa pada akhir siklus. Prosedur pengumpulan data dalam penelitian ini adalah rencana pelaksanaan pembelajaran (RPP), lembar observasi aktivitas siswa, lembar aktivitas observasi guru, lembar kerja siswa (LKS), tes, dan wawancara. Data yang telah terkumpul dianalisis dengan menggunakan teknik analisis kualitatif, salah satu modelnya adalah teknik analisis interaktif yang dikembangkan oleh Miles dan Huberman yang meliputi mereduksi data, menyajikan data, dan menarik kesimpulan serta verifikasi (Moleong, 2006; Putra, 2011; Gunawan, 2014).

\section{HASIL}

Pembelajaran dengan menggunakan model pembelajaran kooperatif tipe Teams Games Tournament (TGT) berbantuan media Kartu Umbul dilaksanakan dalam dua siklus dan terdiri dari 6 kali pertemuan. Materi yang diajarkan yaitu menjumlahkan bilangan bulat dengan menggunakan media kartu umbul, pengurangan bilangan bulat dengan menggunakan media kartu umbul, menyelesaikan masalah yang berhubungan dengan penjumlahan bilangan bulat, dan menyelesaikan masalah yang berhubungan dengan pengurangan bilangan bulat. Sedangkan dua pertemuan lainnya digunakan un- 
tuk melakukan tes akhir setelah Siklus I dan Siklus II.

Langkah-langkah pembelajaran dalam penelitian ini dibagi menjadi tiga kegiatan, yaitu kegiatan awal, kegiatan inti, dan kegiatan penutup. Pada kegiatan awal, peneliti melakukan presensi siswa, kemudian mereview materi pada pertemuan sebelumnya yaitu dengan cara bertanya jawab misalnya tentang penjumlahan bilangan bulat, dan menjelaskan tujuan pembelajaran hari ini. Pada kegiatan inti, peneliti sebagai guru menjelaskan materi bilangan bulat dengan menggunakan media kartu umbul. Kemudian guru meminta siswa untuk berkelompok. Guru juga membagikan LKS. Guru berkeliling membantu siswa yang kurang bisa memahami soal pada lembar tersebut. Setelah selesai mengerjakan, siswa melakukan presentasi hasil kerja kelompok. Dan selanjutnya guru membahas hasil kerja kelompok. Setelah selesai guru memberikan games berupa quiz dengan menggunakan media kartu umbul. Kelompok yang menang akan mendapat penghargaan dari guru. Pada kegiatan akhir, guru bersama siswa merangkum hasil pembelajaran hari ini. Dan guru memberikan tugas rumah.

Untuk mengetahui pemahaman konsep siswa terhadap materi yang telah diberikan oleh guru maka peneliti melakukan tes akhir siklus. Pada saat tes Siklus I dilaksanakan, semua siswa hadir untuk mengikuti tes akhir Siklus I yaitu sebanyak 14 siswa. Dari hasil tes setelah Siklus 1 masih ada sebagian besar siswa kurang memahami tentang materi yang dijelaskan oleh Guru. Hal itu karena banyak siswa belum memahami materi penjumlahan dan pengurangan bilangan bulat. Dan siswa dikatakan tuntas untuk pelajaran matematika di SDN Dinden 1 adalah siswa yang sudah mencapai nilai minimal 65. Berdasarkan nilai yang diperoleh dari hasil tes setelah siklus 1 diketahui bahwa 9 siswa yang mencapai KKM dan 5 orang siswa masih belum mencapai Kriteria Ketuntasan Minimal (KKM). Jadi persentase ketuntasan klasikal adalah $64,29 \%$ atau $35,71 \%$ yang masih belum tuntas. Sehingga persentase pemahaman konsep siswa pada Siklus I adalah $64,29 \%$.

Karena hasil Siklus 1 dinyatakan belum tuntas, maka peneliti melanjutkan siklus yang kedua. Dari hasil tes setelah Siklus II tersebut sebagian besar siswa sudah memahami tentang menyelesaikan masalah yang berkaitan dengan penjumlahan, pengurangan, dan bilangan bulat karena mereka dapat menjawab soal dengan benar. Dan siswa dikatakan tuntas pada pelajaran matematika di SDN Dinden 1 adalah siswa yang sudah mencapai nilai minimal 65. Berdasarkan nilai yang diperoleh dari hasil tes diketahui bahwa 13 siswa yang mencapai KKM dan 1 orang siswa masih belum mencapai KKM. Jadi persentase ketuntasan klasikal adalah $92,86 \%$ atau $7,14 \%$ yang masih belum tuntas. Sehingga persentase pemahaman siswa pada tindakan II adalah 92,86\%. Dari persentase tersebut juga diketahui bahwa pemahaman konsep siswa juga meningkat dari siklus 1 ke Siklus II sebesar $28,57 \%$. Sehingga pemahaman siswa telah dapat dikatakan meningkat. Pada penelitian ini, peneliti juga melakukan pengamatan aktivitas guru dan aktivitas siswa yang dibantu oleh dua observer. Tabel 1 ditampilkan hasil observasi aktivitas guru dan aktivitas siswa.

Berdasarkan Tabel 1 diketahui bahwa hasil observasi dari dua observer diperoleh persentase skor rata-rata pada observasi aktivitas guru selama Siklus I oleh observer I adalah 91,815\% sedangkan observer II yaitu $90,905 \%$ dan rata-rata kedua observer tersebut 91,36\%. Berdasarkan hasil persentase tersebut dapat disimpulkan bahwa aktivitas guru pada pembelajaran siklus I tersebut dalam kriteria sangat baik. Selain itu, kedua observer tersebut juga memberikan penilaian terhadap aktivitas siswa selama siklus I berlangsung. Persentase skor rata-rata pada observasi aktivitas siswa yang diberikan oleh observer I adalah $92,725 \%$ dan observer II memberikan skor ratarata sebesar $90,905 \%$, sehingga diperoleh rata-rata kedua observer tersebut $91,815 \%$. Berdasarkan hasil persentase tersebut dapat disimpulkan bahwa

Tabel 1 Hasil Observasi Aktivitas Guru dan Aktivitas Siswa

\begin{tabular}{ccrrrr}
\hline \multirow{2}{*}{ Siklus } & \multicolumn{2}{c}{ Hasil Observasi Aktivitas Guru } & \multicolumn{2}{c}{ Hasil Observasi Aktivitas Siswa } \\
\cline { 3 - 6 } & & Observer I & Observer II & Observer I & Observer II \\
\hline \multirow{2}{*}{ Siklus I } & Pertemuan I & $89,09 \%$ & $89,09 \%$ & $89,09 \%$ & $87,27 \%$ \\
\multirow{2}{*}{ Siklus II } & Pertemuan II & $94,54 \%$ & $92,72 \%$ & $96,36 \%$ & $94,54 \%$ \\
& Pertemuan I & $92,72 \%$ & $92,72 \%$ & $92,72 \%$ & $92,72 \%$ \\
& Pertemuan II & $96,36 \%$ & $94,54 \%$ & $96,36 \%$ & $94,54 \%$ \\
\hline
\end{tabular}


aktivitas siswa pada pembelajaran pada siklus I tersebut dalam kriteria sangat baik.

Sedangkan hasil observasi dari dua observer diperoleh persentase skor rata-rata pada observasi aktivitas guru selama Siklus II oleh observer I adalah $94,54 \%$ sedangkan observer II yaitu $93,63 \%$ dan rata-rata kedua observer tersebut $94,085 \%$. Berdasarkan hasil persentase tersebut dapat disimpulkan bahwa aktivitas guru pada pembelajaran Siklus II tersebut dalam kriteria sangat baik. Selain itu, kedua observer tersebut juga memberikan penilaian terhadap aktivitas siswa selama Siklus II berlangsung. Persentase skor rata-rata pada observasi aktivitas siswa yang diberikan oleh observer I adalah $94,54 \%$ dan observer II memberikan skor rata-rata sebesar $93,63 \%$, sehingga diperoleh rata-rata kedua observer tersebut $94,085 \%$. Berdasarkan hasil persentase tersebut dapat disimpulkan bahwa aktivitas siswa pada pembelajaran Siklus II tersebut dalam kriteria sangat baik.

Berdasarkan hasil wawancara, diperoleh kesimpulan bahwa siswa telah memahami konsep materi penjumlahan dan pengurangan bilangan bulat serta menyelesaikan masalah yang berkaitan dengan penjumlahan dan pengurangan bilangan bulat. Tujuan pembelajaran yang ingin dicapai sudah cukup dikuasai oleh siswa. Selain itu, berdasarkan wawancara ini juga diperoleh suatu kesimpulan bahwa pemahaman siswa pada materi penjumlahan dan pengurangan bilangan bulat serta menyelesaikan masalah yang berkaitan dengan penjumlahan dan pengurangan bilangan bulat ini sudah bagus dan juga siswa merasa senang belajar dengan menerapkan model pembelajaran kooperatif tipe TGT berbantuan kartu umbul. Berdasarkan hasil analisis ini, semua aspek kriteria keberhasilan pembelajaran yang telah ditetapkan telah tercapai. Dengan demikian disimpulkan bahwa penelitian telah berhasil dan tindakan penelitian tidak perlu dilanjutkan pada Siklus III.

\section{PEMBAHASAN}

Belajar mengenal pada perubahan dan peningkatan kemampuan kognitif, afektif, dan psikomotorik agar dapat melaksanakan perubahan tingkah laku (Hamalik, 2004). Proses belajar mengajar yang baik diupayakan menghasilkan perubahan yang baik pada anak. Pada kenyataanya dalam melaksanakan kegiatan pembelajaran yang dapat mencapai tujuan yang telah ditetapkan bukanlah suatu hal yang mudah. Matematika merupakan salah satu pelajaran yang penting untuk dikuasai oleh siswa karena matematika digunakan dalam berbagai aspek kehidupan manusia. Siswa membutuhkan matematika untuk berhitung, menghitung volume, mengumpulkan, mengolah, menyajikan data, dan lain sebagainya (Hudojo, 2005). Ilmu matematika juga diperlukan untuk bidang ilmu yang lain. Orang membutuhkan matematika agar dapat berbelanja, membaca grafik dan presentasi, membuat catatan-catatan dengan angka, membuat pembukuan, membaca informasi yang disajikan dalam bentuk tabel atau diagram (Effendy, 2007).

Akibatnya pada proses pembelajaran siswa kurang aktif, siswa mudah bosan, interaksi guru terhadap siswa kurang, dan motivasi untuk belajar kurang (Hudojo, 2005). Selain itu, pemahaman siswa terhadapmaterimatematikajugamasihkurang karena banyak siswa mampu menyajikan tingkat hafalan yang baik terhadap materi matematika, tetapi mereka tidak memahami dan sebagian besar siswa kurang mampu menghubungkan materi yang dipelajari dengan penerapannya. Untuk mengatasi masalah tersebut, guru dalam menyelengggarakan kegiatan pembelajaran harus kreatif dalam memilih model pembelajaran yang dapat membantu siswa untuk memahami konsep materi matematika. Salah satunya dengan model pembelajaran kooperatif tipe Teams Games Tournament (TGT). Model pembelajaran kooperatif merupakan salah satu model pembelajaran yang memungkinkan siswa untuk belajar lebih aktif(Ibrahim dan Sukmadinata, 2003).

Keaktifan belajar peserta dapat ditingkatkan melalui model pembelajaran kooperatif tipe TGT dengan media teka-teki silang (TTS) (Nasution, 2012). Siswa pada model ini memainkan permainan dengan anggota-anggota tim lain untuk memperoleh tambahan poin untuk skor tim mereka (Trianto, 2009). Aktivitas belajar dengan model pembelajaran kooperatif tipe TGT dengan perlombaan (turnamen) yang dirancang sedemikian rupa memungkinkan mahasiswa dapat belajar lebih semangat, termotivasi, menumbuhkan tanggung jawab, persaingan yang sehat, dan mahasiswa terlibat langsung dalam kegiatan belajar mengajar (Gunawan, dkk., 2008). 


\section{SIMPULAN DAN SARAN}

\section{Kesimpulan}

Berdasarkan hasil penelitian dan pembahasan, dapat disimpulkan penerapan model pembelajaran kooperatif tipe TGT berbantuan kartu umbul untuk meningkatkan pemahaman konsep siswa Kelas IV SD Dinden 1 Kwadungan Ngawi meliputi tiga kegiatan yaitu kegiatan awal, inti, dan penutup. Selama proses pembelajaran dengan menggunakan model pembelajara kooperatif tipe TGT berbantuan kartu umbul untuk meningkatkan pemahaman konsep siswa Kelas IV SD Dinden 1 Kwadungan Ngawi dapat diketahui bahwa persentase hasil tes Siklus I adalah $64,29 \%$ dan persentase hasil tes Siklus II adalah 92,86\%. Sehingga model pembelajaran kooperatif tipe TGT berbantuan kartu umbul pada materi penjumlahan bilangan bulat, pengurangan bilangan bulat, dan menyelesaikan masalah yang berkaitan dengan penjumlahan dan pengurangan bilangan bulat dapat meningkatkan pemahaman konsep siswa dari Siklus I ke Siklus II yaitu sebesar $28,57 \%$.

\section{Saran}

Beberapa saran yang dapat disampaikan berdasarkan hasil penelitian ini adalah bagi guru, pembelajaran dengan menggunakan model pembelajaran kooperatif tipe TGT berbantuan media kartu umbul dapat dijadikan sebagai salah satu alternatif yang layak dipertimbangkan dalam pembelajaran pada materi penjumlahan bilangan bulat, pengurangan bilangan bulat, dan menyelesaikan masalah yang berkaitan dengan penjumlahan dan pengurangan bilangan bulat. Agar pembelajaran pembelajaran berbantuan media kartu umbul lebih menarik, hendaknya guru memberikan beberapa animasi yang sedang digemari oleh siswa dan gambar-gambar yang relevan serta tidak berlebihan. Sehingga dapat membuat siswa tertarik dan termotivasi untuk memperhatikan penjelasan dari guru. Agar pembelajaran matematika lebih menarik, hendaknya guru menggunakan media dan model pembelajaran yang menarik dan menyenangkan.

\section{DAFTAR RUJUKAN}

Arikunto, S. 2007. Penelitian Tindakan Kelas. Jakarta: PT Bumi Aksara.
Arsyad, A. 2011. Media Pembelajaran. Jakarta: PT Raja Grafindo Persada.

Asnawir, dan Usman, B. 2002. Media Pembelajaran. Jakarta: Ciputat Pers.

Aqip, Z. 2006. Penelitian Tindakan Kelas Untuk Guru. Bandung: Yrama Widya.

Effendy, O. U. 2007. Ilmu Komunikasi: Teori dan Praktik. Bandung: Remaja Rosdakarya.

Gunawan, I. 2014. Metode Penelitian Kualitatif: Teori dan Praktik. Jakarta: PT Bumi Aksara.

Gunawan, I. 2016. Metode Penelitian Kuantitatif, (Online), (http://fip.um.ac.id/wp-content/ uploads/2015/12/2_Metpen-Kuantitatif.pdf), diakses 12 Desember 2016.

Gunawan, I., Wardani, A. D., dan Thohari, A. 2008. Hubungan Penerapan Metode Pembelajaran Kooperatif Model TGT (Teams, Game, and Tournament) Guru Mata Pelajaran Fisika dengan Tingkat Pemahaman dan Motivasi Belajar Siswa SMA Negeri Se-Kota Malang. Laporan penelitian tidak diterbitkan. Malang: Universitas Negeri Malang.

Hamalik, O. 2004. Proses Belajar mengajar. Jakarta: PT Bumi Aksara.

Hudojo, H. 2005. Pengembangan Kurikulum dan Pembelajaran Matematika. Malang: UM Press.

Ibrahim, R., dan Sukmadinata, N. S. 2003. Perencanaan Pengajaran. Jakarta: Rineka Cipta.

Moleong, L. J. 2006. Metodologi Penelitian Kualitatif. Bandung: PT Remaja Rosdakarya.

Nasution, A. M. 2012. Upaya Meningkatkan Keaktifan Belajar Siswa melalui Model Pembelajaran Kooperatif Tipe Team-GameTournament (TGT) dengan Media Tekateki Silang (TTS) pada Mata Pelajaran Ilmu Pengetahuan Alam (IPA) di Kelas IV A MI Sultan Agung Yogyakarta. Laporan penelitian tidak diterbitkan. Yogyakarta: Lembaga Penelitian dan Pengabdian kepada Masyarakat Universitas Negeri Yogyakarta.

Putra, E. D. 2011. Pembelajaran Kooperatif Tipe Investigasi Kelompok untuk Meningkatkan Hasil Belajar Siswa pada Materi Kubus dan Balok Kelas VIII SMP Negeri 2 Batu. Tesis tidak diterbitkan. Malang: Program Pascasarjana Universitas Negeri Malang. 
Trianto. 2009. Mendesain Model Pembelajaran Inovatif Progresif: Konsep Landasan dan Implementasinya pada Kurikulum Tingkat Satuan Pendidikan. Jakarta: Kencana Prenada Media Group.

Winkel, W. S. 2004. Psikologi Pendidikan dan Evaluasi Belajar. Jakarta: PT Gramedia Pustaka Utama. 